\title{
Allergy to selected cosmetic ingredients
}

\author{
Wioletta A. Żukiewicz-Sobczak ${ }^{1}$, Piotr Adamczuk ${ }^{1}$, Paula Wróblewska ${ }^{1}$, Jacek Zwoliński ${ }^{1}$, Jolanta Chmielewska-Badora ${ }^{1}$,

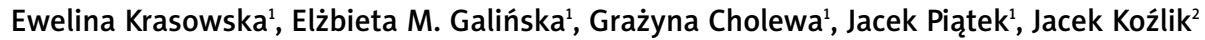

1Department of Allergology and Environmental Hazards, Institute of Rural Health, Lublin, Poland Head of Department: Dr Wioletta A. Żukiewicz-Sobczak

2Department of Physiology, Poznan University of Medical Sciences, Poznan, Poland

Head: Hanna Kraus MD, PhD, Prof. MUP

Postep Derm Alergol 2013; XXX, 5: 307-310

DOI: $10.5114 /$ pdia.2013.38360

\begin{abstract}
In an era in which cosmetics are commonly used, their often prolonged contact with the human body should determine the safety of their use. Often cosmetics are the cause of many side effects, mainly hypersensitivity reactions. Common groups of cosmetic components responsible for side effects are fragrances, preservatives and dyes. This paper focuses on the most allergenic components.
\end{abstract}

Key words: allergy, cosmetics, fragrances, preservatives, dyes.

\section{Introduction}

Nowadays cosmetics are present in everyday life of women, men and children. It is estimated that $95 \%$ of women and $75 \%$ of men have daily contact with cosmetics which, in contrast to external medicines, should not alter the structure and function of tissue to which they are administered [1]. The Polish Act on cosmetics of 30 March 2001 makes it clear that a cosmetic product is any chemical substance or mixture intended for external contact with the human body whose sole or main purpose is to keep it clean, nurture, protect, perfume, change the appearance or improve its scent. This law also regulates the procedures for placing cosmetic products on the market. However, there is still observed incidence of side effects after use of cosmetics, produced by some of their components. The side effect is defined as any unfavorable and unintended operation of the cosmetics used in normal or in other reasonably foreseeable conditions, taking into account all of the instructions for use and any other indication or information provided by the manufacturer [2].

Cosmetics are divided into two groups: left on the skin (leave-on) and rinsed off the skin (rinse-off). The first group includes creams, lotions, perfumes, and they are responsible for the majority of hypersensitivity. Rinsed cosmetics, such as shampoo and other detergents, sensitize significantly less as the contact with skin is short [3].

The extensive literature survey on the application of cosmetics shows that incidence of allergy to components of cosmetics is increasing in many countries $[1,4]$. Research carried out by Thyssen et al. among the citizens of Denmark shows that $56.7 \%$ of women and $33.6 \%$ of men have experienced an adverse effect after using cosmetics at least once in a lifetime [5]. It is estimated that about $10 \%$ of the general population experience side effects, hypersensitivity or allergy-related irritation of cosmetics [1]. According to Wojciechowska et al., side effects occur in about $15 \%$ of people using cosmetics [6]. These data are consistent with the results of research, which estimates that between $8 \%$ and $15 \%$ of all cases of contact dermatitis is caused by cosmetics $[1,7]$.

Adverse reactions mainly depend on the type of the chemical component of the cosmetic product and the exposure time. There is a clear correlation between the frequency of cosmetic applications and the development of allergies. An important factor influencing the formation of contact allergy is also the place of application. The use of cosmetics on irritated or inflamed skin increases the risk of side effects. Fragrances, preservatives and dyes are the most important components contained in cosmetics inducing contact hypersensitivity, while substrates, emulsifiers, stabilizers, viscosity enhancing agents, antioxidants, moisturizing and lubricating substances are less reactive $[1,8]$.

\section{Fragrances}

Fragrances are an essential ingredient in most cosmetics, household products and food. Individual products may con-

Address for correspondence: Dr. Wioletta A. Żukiewicz-Sobczak, Department of Allergology and Environmental Hazards, Institute of Rural Health, 2 Jaczewskiego St, 20-090 Lublin, Poland, phone: +48 698143 743, e-mail: wiola.zukiewiczsobczak@gmail.com Received: 7.08.2013, accepted: 10.09.2013. 
tain from 10 to 300 these compounds. The largest number of them are contained in perfumes in which fragrance may reach even $60 \%$ (in perfume extract). The perfume industry uses about 3,000 kinds of flavors, which are obtained from natural products or are synthesized [9].

Given the wealth of fragrance compounds used in cosmetics, a mixture of several most allergenic compounds is used in the contact allergy screening test. A mix of eight common fragrances (Fragrance Mix - FM) is commonly used for testing fragrance contact allergy. Patch tests are equally well performed with balsam of Peru [10].

According to some researchers, FM test detects sensitivity to odors, even in $70 \%$ of allergic persons [11], but many studies have reported that the percentage is much lower, at around 30\% [12-14]. The mix consists of the cinnamic aldehyde and alcohol, eugenol and isoeugenol, geraniol, hydroxycitronellal, amyl cinnamaldehyde, and oak moss. A study conducted in Denmark on about 10,000 patients with eczema showed that $5.5 \%$ of respondents reported positive reaction after exposure to the mix. Most commonly an allergenic reaction to oak moss was found, the second consecutive sensitizing compound was isoeugenol, followed by the cinnamic aldehyde, cinnamic alcohol, eugenol, hydroxycitronellal, geraniol and finally amyl cinnamaldehyde $[15,16]$. An allergy to oak moss and isoeugenol, which are part of deodorants and expensive perfume, is so common that both were called for the prohibition of adding them to the cosmetics in the European Union [16]. Efforts were also made to replace isoeugenol with its acetate, but it did not give satisfactory results [17].

Balsam of Peru is also the addition of fragrance in many cosmetics, and its use is wide due to fixative properties. At least a dozen allergens are behind the commonly known name of this product, and they include cinnamic aldehyde and acid, cinnamic cinnamon, cinnamon benzoate, benzyl benzoate, vanillin, vanillic acid, nerolidol and farnesol. Due to the existence of so many components, balsam of Peru has a high risk of cross-reactions [18].

Five to fourteen percent of patients with eczema are allergic to cosmetic perfumes $[19,20]$. However, it is estimated that the sensitivity to fragrance products occurs in $1-16 \%$ of unselected population. Hypersensitivity to fragrances usually occurs in the form of allergic contact dermatitis, contact urticaria, and phototoxic reactions. These changes relate to various areas of the skin, including the face, neck, armpits, or hands [21, 22].

\section{Preservatives}

Preservatives provide durability and protection against the growth of bacteria and fungi that cause cosmetics to decay. Disinfectant properties of paraaminobenzoic acid esters (parabens), formaldehyde-releasing compounds, isothiazolinones, organic compounds of mercury (thiomersal) are commonly used in cosmetics [23]. These compounds have a very different chemical structure and can be divided into the following groups: alcohols, amides and amines, carbanilides, formaldehyde donors and metals, organics [24].

In the group of preservatives, special attention should be paid to thiomersal (synonyms: merthiolate, thimerosal, vitaseptol), which is an organic mercury compound of thiosalicylic acid. Its maximum concentration may be $0.007 \%$ (based on mercury) [25]. It is commonly found in cosmetics such as eye shadows, mascaras, lotions, contact lens solutions and ophthalmic preparations. This preservative is also used in vaccines and many other products [26]. Thiomersal has antibacterial and antifungal properties, without irritating the skin and mucous membranes. However, many studies clearly indicate that the incidence of positive patch test results with thiomersal is very high [27]. Some studies have reported that contact allergy to thiomersal affects approximately $18.5 \%$ of young people [28].

Formalin (aqueous formaldehyde solution) and formaldehyde donors have high priority among the preservatives which are present in allergy for cosmetics. Formalin is an excellent preservative with a specific, unpleasant smell, which is neutralized with added special perfume. This compound is widely used not only as a preservative, but also in the production of many plastics. For this reason, the cause of the allergy is sometimes problematic. Formaldehyde is a relatively potent contact allergen, and therefore formaldehyde donors are increasingly being used to reduce its concentration by slow release. However, numerous studies have reported that the proposed formaldehyde-releasing preservatives sometimes cause an allergic reaction, and in addition there may be a concurrent adverse reaction to formaldehyde [8, 25, 29].

Remarkable preservatives are esters of para-hydroxybenzoic acid called parabens. Chemically, they are primarily esters of methyl, ethyl, propyl, butyl and benzyl p-hydroxybenzoate. Shorter chain esters are effective against bacteria, and long-chain esters are more active against fungi, and therefore mixtures of these compounds are normally used; however, for the study of allergy almost always 3 esters (methyl, ethyl and propyl) are present in the composition. These compounds are present in almost all (99\%) leave-on cosmetic products and in a large part (77\%) of rinse-off cosmetics, and its concentration can be up to $0.8 \%$ [30]. Parabens are, however, relatively weak allergens and produce an allergic reaction as often as components of drugs, when applied on damaged skin [23].

\section{Dyes}

Another substance which is incorporated in cosmetics, which is also a frequent cause of allergies, is paraphenylenediamine (PPD). It is primarily a component of hair dyes and coloring shampoos and many color cosmetics [23, 31]. Paraphenylenediamine is a member of "para-amino" compounds, i.e. aromatic amines, which can cause cross reactions and secondary allergy to other hair dyes and textiles in a person highly allergic to PPD [32]. 
The Polish literature assesses the incidence of hypersensitivity reactions to PPD at $3.4 \%$ to $9.1 \%$ of the general population [33, 34]. However, the black dye is the cause of allergies mainly in professional groups regularly exposed to it, such as hairdressers and beauticians. According to Valks et al., 50\% of hairdressers are sensitized to PPD [35]. The source of allergies in beauticians is often artificial henna which includes PPD. Artificial henna can often cause allergy, particularly in young people who draw impermanent tattoos [31]. Currently, an increased tolerance to PPD among users of color cosmetics is explained by the increased purity of cosmetics. In the past, among women dyeing eyelashes with artificial henna, there were cases of so severe reactions that it caused damage to the cornea $[36,37]$. There are many other dyes such as toluidine red, calcium salts of lithol red, or lead oxide, which may be the cause of allergic reactions [38].

Many dyes are substances that can cause phototoxic or photoallergic reactions; these include eosin, rose bengal, methylene blue, anthraquinone. Such reactions occur under exposure to ultraviolet light, which modifies the substances on the skin, so that this may be associated with skin proteins and become a competent photoallergen. Repeated exposure to this compound, while exposed to UV radiation causes an allergic reaction of the delayed type, as in allergic contact dermatitis. Eosin, deep red dye, is a perfect example of a photoallergic reaction agent. In persons exposed to eosin, irritation and sweating of fingers as well as blisters on fingers were observed. This dye is used in cosmetics manufactured in Asia and the Arab countries. Due to the sensitization it was withdrawn from the European and the U.S. markets $[39,40]$.

\section{Summary}

Despite the control of the production of cosmetics and withdrawal of the composition of substances causing adverse reactions in people, harmful compounds found in cosmetics still pose a major problem. It even turns out that allergy to components of cosmetic disease is increasing. In order not to replace withdrawn, highly allergenic substances, with new ones which also cause adverse side effects, allergies to cosmetics should be constantly monitored.

\section{References}

1. Wolf R, Wolf D, Tüzün B, Tüzün Y. Cosmetics and contact dermatitis. Dermatol Therapy 2001, 14: 181-7.

2. Hałat Z. Adverse reactions to cosmetics [Polish]. Alergia 2003; 36-40.

3. Thomson KF, Wilkinson SM. Allergic contact dermatitis to plant extracts in patients with cosmetic dermatitis. Br J Dermatol 2000; 142: 84-8.

4. Lunder T, Kansky A. Increase in contact allergy to fragrances: patch-test results 1989-1998. Contact Dermatitis 2000; 43: 107-9.
5. Thyssen JP, Linneberg A, Menné T, et al. The prevalence and morbidity of sensitization to fragrance mix I in the general population. Br I Dermatol 2009; 161: 95-101.

6. Wojciechowska M, Gocki J, Bartuzi Z. The occurrence of cosmetics side effects. In: Selected aspects of health care [Polish]. Bartuzi Z (ed.). Nicolaus Copernicus University, Bydgoszcz 2007; 524-8.

7. Polańska A, Dańczak-Pazdrowska A, Silny W, et al. Evaluation of selected skin barrier functions in atopic dermatitis in relation to the disease severity and pruritus. Postep Derm Alergol 2012; 29: 373-7.

8. Klimańska M, Żmudzińska M, Jenerowicz D, Czarnecka-Operacz $M$. The importance of exposure to contact allergens in patients with allergic contact dermatitis. Postep Derm Alergol 2011; 28: 203-11.

9. Dharmagunawardena B, Takwale A, Sanders KJ, et al. Gas chromatography: an investigative tool in multiple allergies to essential oils. Contact Dermatitis 2002; 47: 288-92.

10. Rudzki E. Allergens [Polish]. Medycyna Praktyczna, Kraków 2008; 275-449.

11. De Groot AC, Frosch PJ. Adverse reactions to fragrances. A clinical review. Contact Dermatitis 1997; 36: 57-86.

12. Rastogi SC, Menné T, Johansen JD. The composition of fine fragrances is changing. Contact Dermatitis 2003; 48: 130-2.

13. Frosch PJ, Johansen JD, Menné T, et al. Further important sensitizers in patients sensitive to fragrances. I. Reactivity to 14 frequently used chemicals. Contact Dermatitis 2002; 47: 78-85.

14. Larsen WG. How to test for fragrance allergy. Cutis 2000; 65: 39-41.

15. Johansen J, Menne T. The fragrance mix and its constituents: a 14-year material. Contact Dermatitis 1995; 32: 15-23.

16. Hendriks S, Ginkel C. Evaluation of the fragrance mix in the European Standard Series. Contact Dermatitis 2000; 41: 161-4.

17. White I, Jonhsen J, Arnau E, et al. Isoeugenol as an important contact allergen. Contact Dermatitis 2000; 49: 272-5.

18. Rastogi S, Johansen J, Menne T. Natural ingredients based cosmetics. Content of selected fragrance sensitizers. Contact Dermatitis 1996; 34: 423.

19. Kiec-Świerczyńska M, Kręcisz B, Świerczyńska-Machura D. Contact allergy to fragrances [Polish]. Med Prakt 2006; 57 : 431-7.

20. Gregorius A, Śpiewak R. A comparison of patch test results with the European Baseline Series, Polish Baseline Series and an original extended series in the diagnosis of patients with suspected contact allergy [Polish]. Alergoprofil 2011; 7: 25-31.

21. Schäfer T, Böhler E, Ruhdorfer S, et al. Epidemiology of contact allergy in adults. Allergy 2001; 56: 1192-6.

22. Heydorn S, Johansen JD, Andersen KE, et al. Fragrance allergy in patients with hand eczema - a clinical study. Contact Dermatitis 2003; 48: 317-23.

23. Kiec-Świerczyńska M, Kręcisz B, Świerczyńska-Machura D. Contact allergy to para-(amino) compounds in European Standard Series [Polish]. Przegl Dermatol 2008; 3: 287-92.

24. Campana R, Scesa C, Patrone E, et al. Microbiological study of cosmetic products during their use by consumers: health risk and efficacy of preservative systems. Lett Appl Microbiol 2006; 43: 301-6.

25. Streinberg D. Preservatives for cosmetics. Allured Publishing 2006.

26. Breithaupt A, Jacob SE. Thiomersal and the relevance of patch-test reactions in children. Dermatitis 2008; 19: 275-7. 
W.A. Żukiewicz-Sobczak, P. Adamczuk, P. Wróblewska, J. Zwoliński, J. Chmielewska-Badora, E. Krasowska, E. M. Galińska, G. Cholewa

27. Wöhrl S, Hammer W, Focke M, et al. Patch testing in children, adults and the elderly: influence of age and sex on sensitization patterns. Pediatr Dermatol 2003; 20: 119-23.

28. Śpiewak R. Contact allergy - diagnosis and treatment [Polish]. Alergia Astma Immunologia 2007; 3: 109-26.

29. Tanglertsampan C. Allergic contact dermatitis from formaldehyde with initially negative repeated open application test. Contact Dermatitis 2003; 48: 171-2.

30. Rastogi S, Schouten A, de Kruijf N, et al. Contents of parabens in cosmetic products. Contact Dermatitis 1995; 32: 28-30.

31. Marcoux D, Couture-Trudel PM, Riboulet-Delmas G, et al. Sensitization to para-phenylediamine from a street temporary tatoo. Pediatr Dermatol 2002; 19: 498-502.

32. Seidenari S, Manzini B, Danese P. Cross sensitization between azo dyes and paraamino compounds. Contact Dermatitis 1997; 36: 91-6.

33. Rudzki E, Rebandel P. Sensitivity to paraphenylenediamine in Warsaw (Poland). Contact Dermatitis 2007; 57: 347-8.

34. Reduta T, Laudańska H. Contact hypersensitivity to topical corticosteroids - frequency of positive reactions in patchtested patients with allergic contact dermatitis [Polish]. Przegl Dermatol 2005; 6: 429-35.

35. Valks R, Conde-Salazar L, Malfeito J, et al. Contact dermatitis in hairdressers, 10 years later: patch-test results in 300 hairdressers (1994 to 2003) and comparison with previous study. Dermatitis 2005; 16: 28-31.

36. Uter W, Schnuch A, Geiger J, et al. Epidemiology of contact dermatitis. Eur I Dermatol 1997; 1: 36-40.

37. Krasteva M, Cristaudo A, Hall B, et al. Contact sensitivity to hair dyes. Eur I Dermatol 2002; 12: 322-5.

38. Pierzchała E, Lis-Święty A. Allergy to cosmetics on lips and perioral region [Polish]. Dermatol Estet 2005; 7: 273-6.

39. Kręcisz B. Photodermatoses. In: Principles of diagnosis, case law and the prevention of occupational diseases of the skin [Polish]. Kieć-Świerczyńska M. (ed.). Postgraduate Medical Education Center, Warsaw 2010; 85-93.

40. Braun-Falco O, Plewig G, Wolff HH, Burgdorf WHC. Dermatology [Polish]. Czelej, Lublin 2004. 